and is convinced that "in the systems of scientific knowledge progress can be measured in terms quite independent of value judgments" (p.4). Newton's worldview, he argues, represents progress over Aristotle's because "Newtonian theory is bigger, more exact, more precisely testable, and above all more mathematical than its predecessor." Hall views the history of science as a branch of the history of ideas. Surprisingly, he equates the force of Newtonian ideas with the force of Lenin's ideas (p.360).

Hall has ignored, or rather, neglected to include in his treatise any accounts of the social relations of science, and little of the political relations. Martin Luther, for example, warrants mention only three times, and these mentions are incidental; it is not until page 348 that the reader is reminded that war separated the French and the English from 1698 to 1714. Hall's second chapter, 'The Problem of Cause' may be regarded as an attempt to deal with the issues raised by the sociologists of science, but most of the scholarship is dealt with indirectly, by refutation. The reader is told why Thomas Kuhn's The Structure of Scientific Revolutions (University of Chicago) should not be applied to the scientific revolution of $1500-1750$ but Kuhn's work is not directly cited in this connection (citations to it do appear elsewhere). Merton's thesis about the role of Protestants in the founding of the Royal Society is rejected, although there is an acknowledgement that Christopher Hill and Charles Webster have found it seminal. Hall deals handsomely with Dame Frances Yates's magisterial Giordano Bruno (Routledge), but rejects its operating thesis. These are, of course, exactly the positions to be expected from someone who sees the history of science as a sub-set of the history of ideas.

In sum, Hall's book tacitly redefines the term 'scientific revolution' by concentrating almost exclusively on changes in astronomy, mechanics and biology, removing from consideration changes in chemistry and electricity; the scientific revolution is seen as a triumph of mathematicization, as the progress of rationality over religiosity, above all, as an 'internal' process depending almost exclusively on 'progress' within a discipline. There is no doubt in this reviewer's mind that if what is wanted is such an 'internal' history, Hall's book is one of the best of the genre. The prose is lucid, the structure of each chapter (and of each paragraph) is rhetorically exemplary and graceful. Graduate students, those with some knowledge of the literature, should find the book rewarding reading; undergraduates will be confused by it. Non-historians, especially those with 'internalist' or whiggish proclivities will find here storng confirmation of their own convictions.

J.Z. Fullmer is a Professor of History at the Ohio State University, Columbus, Ohio.

\section{The ascent of}

\section{man}

\section{Robert Fox}

The Montgolfier Brothers and the

Invention of Aviation 1783-1784.

By Charles Coulston Gillispie.

Princeton University Press: 1983. Pp. 210. \$45, £30.20.

THE first public demonstration of a hot-air balloon took place on 4 June 1783 at Annonay in France. The setting, in a remote, hilly part of what is now the department of the Ardèche, was an improbable one, and the curious onlookers who gathered in the town's square could hardly have appreciated the momentousness of a flight that lasted a mere ten minutes and ended frighteningly with the sackcloth and paper of the balloon's fabric set alight by the fire of its brazier. But within weeks the brothers who mounted the demonstration, Joseph and Etienne Montgolfier, had leapt from provincial obscurity to the rank of national celebrities, and they have remained celebrities ever since.

Charles Gillispie devotes the greater part of his gracefully written book to an account of the circumstances of the Montgolfiers' invention and of the early heroic years of aviation in France. It is a story bristling with dramatic events and colourful characters. From the start, spice was added to the episode by the initial, mistaken assumption of the Parisian savants that the Annonay balloon must have been raised by hydrogen. The result was a rivalry, which the Montgolfiers never sought, between the

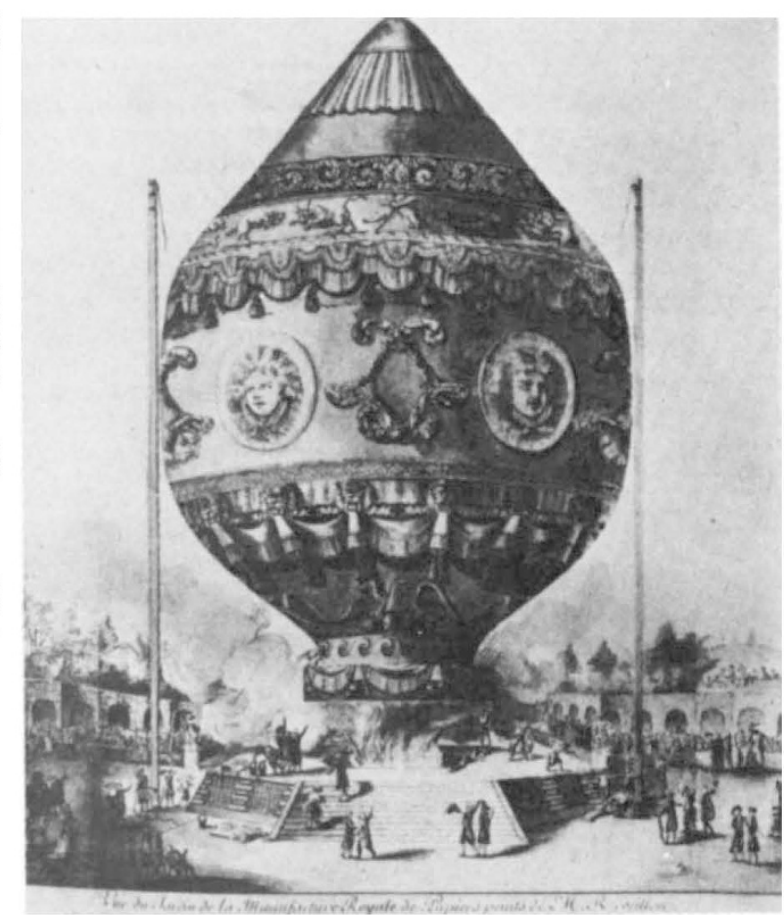

Testing an early balloon - October 1783. hot-air montgolfière and the hydrogen balloon, or charlière, named after the physicist J.A.C. Charles, who was a notable pioneer of hydrogen ballooning.

The degree of popular interest was extraordinary, and grand public demonstrations became the order of the day. In September 1783, Etienne Montgolfier staged a particularly memorable flight for the king and queen at Versailles and on 21 November 1783 the inevitable next step was taken when a prominent scientific lecturer, Pilatre de Rozier, and an infantry officer, the marquis d'Arlandes, undertook the first manned flight in an untethered balloon. Ironically, it was Pilatre de Rozier who became the first victim of aviation in June 1785, when his hazardous attempt to use a hydrogen balloon and a hot-air balloon in tandem ended in an all too predictable disaster. But even that wellpublicized tragedy did nothing to dampen enthusiasm. Ascents continued to attract large crowds, and the risks only added to the stature of professional aviators, several of whom earned a good living by their displays. The public's appetite for daring deeds was insatiable until well into the nineteenth century, and it is only surprising that accidents (such as the one that led to the death of the colourful Madame Blanchard as she injudiciously enlivened her ascent in a hydrogen balloon by letting off fireworks) were so few in number.

The conviction that ballooning quickly became an altogether too sensational affair is unavoidable. This was certainly the view of the Montgolfiers, whose hearts and principal means of livelihood remained in their paper-making business back in the Vivarais, and the high jinks and attractive iconography have been a snare for historians ever since.

But this book dispels the idea that early ballooning was nothing more than an unscientific activity divorced from all seriousness. The reinterpretation is an important one, resting on printed sources, letters, and notebooks that have been hitherto unread or inadequately exploited; and it appears unchallengeable. The theoretical content of the Montgolfiers' work may have been unconventional, but it was substantial and, in significant respects, original, as Gillispie demonstrates. He shows Etienne Montgolfier engaged in calculations of the lifting power of balloons ('the bigger the better' was the gist of his conclusions) and embarking on the design of paddles for a dirigible balloon. And, most interestingly, he points to 
Joseph's abiding curiosity about the relations between heat and mechanical work.

Clearly, it is hard to know just how farseeing these wider reflexions were. Unlike his better-educated brother, Joseph was a doer, a self-taught inventor, rather than a savant. But it seems likely that from the 1780 s until his death in 1810 , he groped some way towards the notion that heat and work are interchangeable. This, at all events, was the retrospective view of the engineer Marc Seguin, a great-nephew of the Montgolfiers who, as a child, had known and learned from Joseph. Gillispie's careful re-examination of the evidence suggests that Joseph's ideas probably originated in his work on an ingenious heat-pump, a device that raised water by means of the heat produced in the rapid explosion of hydrogen or the burning of faggots. Thereafter, it survived through

\section{Megalithic points}

\section{Clive Ruggles}

\section{Echoes of the Ancient Skies: The \\ Astronomy of Lost Civilizations. \\ By E.C. Krupp.}

Harper and Row: 1983. Pp.386. £16.95.

POPULAR books on archaeoastronomy continue to issue forth from the presses once a year or so, although the emphasis has changed distinctly since the 'Stonehenge Decoded' debate of the 1960's which started it all, and again since the more recent controversies over Alexander Thom's theories on megalithic 'science'. The current message is that astronomy is a sacred rather than a 'scientific' activity; and that in studying archaeoastronomy we are exploring the belief systems, ceremonial activities and cosmologies of diverse societies past (here we now include the great literate civilizations) and present (in this case, for 'archaeoastronomy' read 'ethnoastronomy').

The subject matter of Krupp's book (excluding what amounts to a rather incongruous swift potted history of cosmology in the final chapter in order, apparently, merely to make a concluding point about "why we do it") reflects a change in the definition of archaeoastronomy which is all to the good; archaeoastronomy is beginning to find its feet as a respectable branch of archaeology and ethnography. There is talk of how rituals serve to demarcate and regulate time periods (hardly a new point to anthropologists, admittedly) and hence tend to be related to astronomical observations; and of how the extent of astronomical practice can relate to a society's complexity. It is good to see such points stressed at intervals throughout Echoes of the Ancient Skies, and illustrated with a variety of examples.

Yet I feel, such success has been achieved a series of related inventions of which at least one, the hydraulic ram, was favourably viewed by the leading scientists of the capital. I find the historical significance of this work as intriguing as Gillispie obviously does, though it throws up tantalizing possibilities rather than a justification for a major reinterpretation of the prehistory of thermodynamics.

Despite the loose ends, it is hard to imagine that there is very much more to be said on the Montgolfiers and their world. However, quite apart from its scholarly merits, the book can be recommended as a good read. The work of any historian has its drab moments, but the wit and liveliness of Gillispie's text suggest that in this case such moments were few and far between. $\square$

Robert Fox teaches the history of science at the University of Lancaster. At present, he holds a British Academy Readership in the Humanities.

in the face of, rather than owing to, the thematic way in which the material has been organized. The Maya civilization (to take an extreme example) crops up in no less than six different chapters and might arguably have appeared in one or two more. On the other hand, in the 'Skies we Watch' chapter we are taken in the short space of $\mathbf{4 0}$ pages from ancient Egypt to Shang dynasty China, thence to Babylon, pre-conquest Illinois, prehistoric Scotland and Brittany, the Inca in Peru, the Maya in Mexico, and finally back to ancient China.

All this leaves the reader breathless if not a little confused and at times, as one apparently unrelated description follows another, perhaps even slightly bored; this despite Krupp's enthusiasm and readable. style, and the originality and excitement of much of the subject matter. Attempts to draw threads together are too few and far between, and I wonder if, in the end, archaeoastronomy doesn't come over to the average reader primarily as the mere documentation of astronomical practice.

Krupp has to some extent played down controversy in order to present the evidence for ritual astronomy as a coherent whole. This is defensible for a popular book, but care is needed that a new popular bandwagon (albeit less fantastic than previous ones) does not start rolling.

Already ideas of ritual astronomy are running well ahead of the evidence in some areas, notably the megaliths (where serious debate continues, on the basis of extensive new site surveys and new methodology, about the precision and often the very existence of significant astronomical alignments). I feel that Krupp might have emphasized these areas: by doing so his book would have been truer to the spirit of much current serious archaeoastronomical research, and might have attracted a more discerning readership.

Clive Ruggles is a Research Fellow in the Department of Mathematics at the University of Leicester.

\section{Falling apples and leaning towers}

\author{
John D. Barrow
}

\section{Frame of the Universe:}

A History of Physical Cosmology.

By Frank Durham and

Robert O. Purrington.

Columbia University Press: 1983.

Pp.275. \$32.50, £22.

'HISTORY repeats itself; historians repeat each other'; the natural reaction perhaps of someone seeing another medium-brow guide to the history of science. A sufficient number of such surveys already exist to create a form of '1066 and all that' subculture within the subject. Those events that never happened live most vividly in the mind and are much more memorable than those that really did: Newton's falling apple; Archimedes' bath, Galileo and the tower of Pisa - all are cornerstones of the sub-culture.

The authors of the 'Frame of the Universe' have chosen to follow the history of cosmological ideas from ancient to modern times at a level suitable for nonspecialist college courses and general reading. They claim no great novelty in their treatment and erect their frame around the first ancient and Greek astronomers, the Medievals, Copernicus, Galileo and Newton, before moving on to Einstein, modern big bang cosmology and gravitational collapse. Yet, the clarity of presentation and the engaging style of the authors make this an enjoyable book for any scientist to read. Those wishing to pursue subjects in greater depth are provided with an excellent bibliography and detailed notes.

One of the problems with histories of this sort is that our own categories of thought so influence the presentation. We view the past solely in terms of the route necessary to reach the (right) answers of the present. The failures are ignored as inessential byproducts of a never-faltering march towards the 'truth'. This 'Whig' approach to the history of science is the one that prevails in the minds of most working scientists with a passing interest in the history of their subject and, although the authors are aware of this snare, they do not make any real effort to avoid it. The other weak point in the overall treatment, which will be disappointing to many students reading the book, is that whereas the authors are very lucid in describing the course of events, they are weak on the explanatory side. They rarely ever ask the interesting question 'Why'. Why, for example, did the Jews take no interest in astrology? What role did their religious beliefs play, and so forth.

In the opening chapters there is a particularly clear discussion of various megalithic 'observatories', including Stone- 